\title{
In vitro silencing of the insulin receptor attenuates cellular accumulation of fibronectin in renal mesangial cells
}

\author{
Naohiro Yano ${ }^{*}$, Daisuke Suzuki², Masayuki Endoh², Weizhi Zhang ${ }^{3}$, Yan Chun Xu', James F Padbury ${ }^{1}$ \\ and Yi-Tang Tseng ${ }^{1 *}$
}

\begin{abstract}
Background: Insulin receptor (InsR) and insulin signaling proteins are widely distributed throughout the kidney cortex. Insulin signaling can act in the kidney in multiple ways, some of which may be totally independent of its primary role of the maintenance of whole-body glucose homeostasis. However, descriptions of the insulin signaling in renal glomerular mesangial cells (MCs) are quite limited and the roles of insulin signaling in MC functions have not been sufficiently elucidated.
\end{abstract}

Results: InsR silencing induced a unique phenotype of reduced fibronectin (FN) accumulation in renal glomerular MCs. Transcription level of FN was not significantly changed in the InsR silenced cells, suggesting the phenotype switching was caused by post-transcriptional modification. The decreased expression of InsR was associated with enhanced activity of insulin-like growth factor-1 receptor (IGF-1R)/PI3K/Akt signaling pathway which contributed in part to the attenuation of cellular FN accumulation. Formation of IGF-1R homodimer was increased in the InsR silenced cells. The InsR silenced cells also showed increased sensitivity to exogenous IGF-1, and increased PI3K activity was reversed significantly by incubating cells with IGF-1R specific antagonist, AG538. PI3K/Akt dependent activation of CAMP responsive element-binding protein (CREB)-1 induced expression of matrix metalloproteinase (MMP)-9 and suppressing MMP activity by doxycycline partially reversed FN accumulation in the InsR silenced cells.

Conclusions: The effects of InsR silencing on cellular FN accumulation in vitro are, at least partially, mediated by increased degradation of FN by MMPs which is induced by enhanced signaling sequence of IGF-1R/PI3K/Akt/ CREB-1.

Keywords: Insulin receptor, Fibronectin, Mesangial cells, CREB-1, MMP-9

\section{Background}

One of the common local pathologic changes of glomerulonephropathy is accumulation of extracellular matrix (ECM) components, including fibronectin (FN), which results in glomerulosclerosis. Although the mechanisms responsible for the ECM protein deposition are still inconclusive, the role of renal glomerular mesangial cells (MCs) in this sclerotic change has been gathering increasing attentions. Glomerular mesangium is an area which shows the most prominent ECM accumulations in

\footnotetext{
*Correspondence: nyano@wihri.org; ytseng@wihri.org

'Department of Pediatrics, Women \& Infants Hospital, The Warren Alpert

Medical School of Brown University, Providence, RI 02905, USA

Full list of author information is available at the end of the article
}

diseased kidney. And the resulting glomerular fibrosis has been recognized as the major degenerative event in glomerulonephropathies regardless of their etiologies [1-3]. MCs are specialized pericytes located among the mesangium area within the renal corpuscle of the kidney [4]. ECM protein deposition could be caused by matrix deposition exceeding matrix degradation. Many studies have focused on a possible imbalance of in situ synthesis and degradation of ECM proteins in glomeruli $[5,6]$. Indeed, some animal experiments have shown that the accumulation of ECM proteins in focal segmental glomerulosclerosis is associated with increased ECM protein synthesis coupled with suppression of expression or activity of proteolytic enzymes, including cathepsins and

C Biomed Central

(c) 2012 Yano et al.; licensee BioMed Central Ltd. This is an Open Access article distributed under the terms of the Creative Commons Attribution License (http://creativecommons.org/licenses/by/2.0), which permits unrestricted use, distribution, and reproduction in any medium, provided the original work is properly cited. 
matrix metalloproteinases (MMPs) [6-8]. Mesangial cells secrete MMPs that degrade intact glomerular basement membrane, gelatin, soluble type IV collagen and FN at neutral $\mathrm{pH}[5,9]$. MMPs and their specific inhibitors, tissue inhibitor of metalloproteinases (TIMPs), play an important role in regulating glomerular matrix remodeling $[5,9,10]$. Based on these findings, besides their three primary functions, that is, filtration, structural support, and phagocytosis, MCs have been postulated to be a key player for FN regulation in the kidney and is speculated as one of the major contributors to the sclerotic lesion in glomeruli [11].

The insulin receptor (InsR) and insulin signaling proteins are widely distributed throughout kidney cortex $[12,13]$. Insulin signaling can act in the kidney in multiple ways, some of which may be totally independent of its primary role of the maintenance of whole-body glucose homeostasis. As for renal tissue, the roles for insulin signaling in tubular epithelial cells have been described extensively in previous studies. The signaling is clearly anti-natriuretic, affecting sodium reabsorption in the proximal tubule [14], thick ascending limb [15,16], and collecting duct [17]. In contrast, descriptions of insulin signaling in MCs are limited and the roles of insulin signaling in $\mathrm{MC}$ functions have not been sufficiently elucidated.

The InsR and IGF-1R are structurally related transmembrane glycoproteins with approximately $50 \%$ amino acid sequence identity [18]. Post-translational processing results in dimerization and disulphide linkage of proreceptors. This is followed by proteolytic cleavage, which generates $\alpha$ and $\beta$ subunits [19]. Mature and functional receptors thus have the subunit composition of $(\alpha \beta)_{2}$. The extracellular $\alpha$ subunit contains a ligand binding site and the transmembrane $\beta$ subunit possesses tyrosine kinase activity. The distinct physiological functions of insulin and IGFs depend on differences in the distribution and/or signaling potential of their respective receptors. Despite of this, it has been shown that a proportion of InsR and IGF-1R assemble as hybrid structures containing an $(\alpha \beta)$ half of the InsR disulphide-linked to an $\left(\alpha^{\prime} \beta^{\prime}\right)$ half of the IGF-1R [20-22]. These hybrid receptors are functional, in that they bind IGF-1 with high affinity and insulin with somewhat lower affinity $[23,24]$, and display IGF-1-induced autophosphorylation both in vitro and in situ $[24,25]$. MCs express both InsR and IGF-1R $[11,26]$ and therefore have the potential to form functional hybrid receptors. However, the significance of hybrid receptors in MCs remains unclear.

Here, we explore the roles of InsR/IGF-1R signaling in cellular FN accumulation, using a SV40 immortalized mouse mesangial cell line, MES-13. With silencing InsR expression by shRNA, the cells showed significant reduction of cellular FN accumulation. The aim of the present work was to identify responsible alterations of the signaling pathway for the phenotype switching. We provide evidences that rearrangement in the balance between insulin and IGF-1 receptor homodimers and hybrid receptors contributed to the phenotype switching. We also demonstrate cAMP responsive element-binding protein (CREB-1) and MMP-9 as downstream factors for the attenuation of cellular FN accumulation.

\section{Results}

\section{InsR silencing in MES-13 cells}

Twenty clones of shRNA against InsR transfected cells were tested for their phenotypes. Cells were seeded in $2 \times 10^{5} / \mathrm{ml}$ density. The next day, serum was deprived from the medium for 16 hours. The quiescent cells were harvested and lysates were subject to Western blotting for InsR $\alpha$. Three clones (\#7, 11 and 13) which showed more than $85 \%$ suppression of InsR expressions were employed in the experiments (Figure 1).

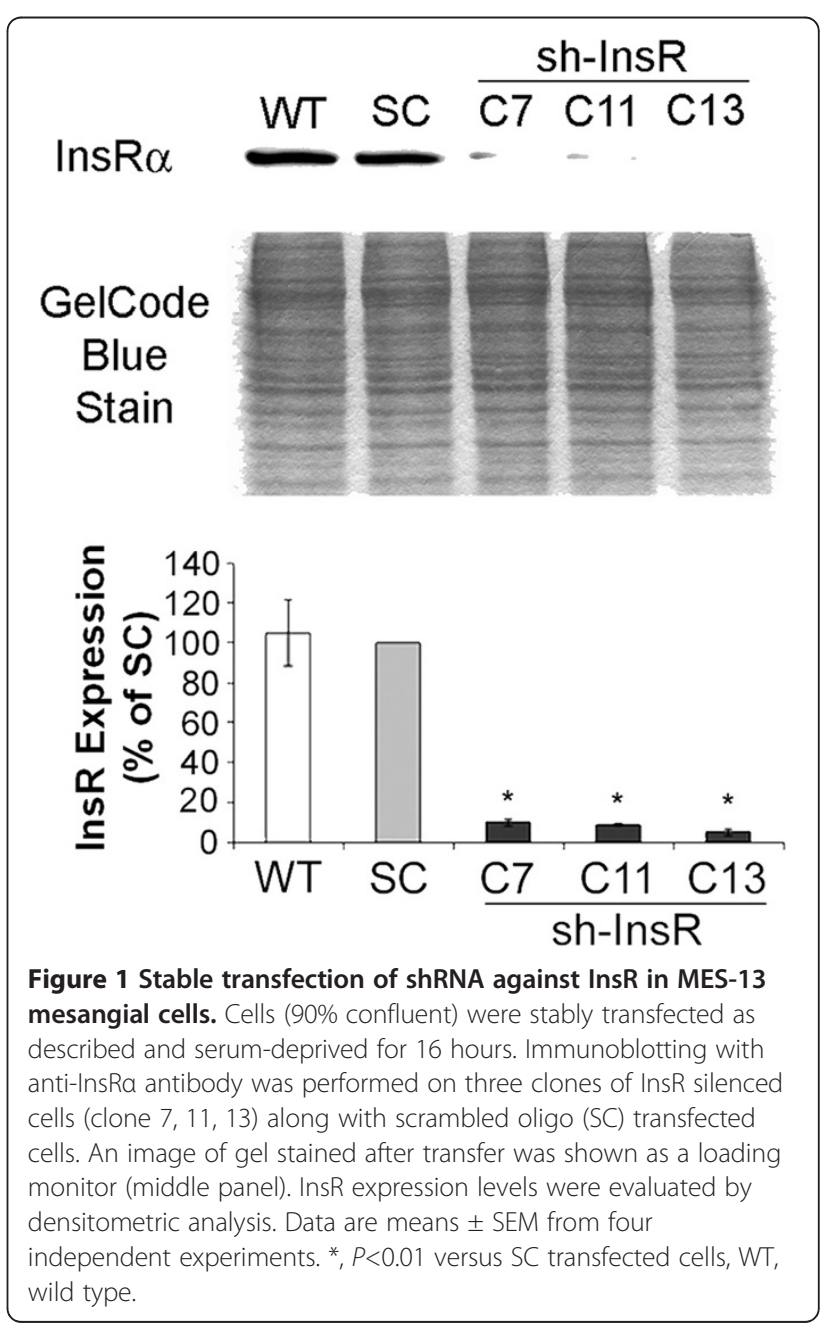




\section{Cellular FN accumulation is attenuated in the InsR silenced cells}

Cell lysates from InsR silenced or scrambled oligo plasmid (SC) transfected cells were harvested as described above, and then served for Western blotting or semiquantitative RT-PCR for FN. The InsR silenced cells showed remarkably decreased cellular FN accumulation, but no changes in transcriptional level of FN (Figure 2A, B). This finding suggested that the attenuation of cellular FN accumulation in InsR silenced cell is due to posttranscriptional modification.

\section{Activation of PI3K/Akt pathway and suppression of Ras/Erk1/2 in the InsR silenced cells}

The cell lysates were subject to in vitro lipid kinase assay for measurement of PI3K activity. InsR silencing induced a significant increase in PI3K activity (Figure 3A). Phosphorylation of Akt and p70S6 kinase (p70S6K), two important downstream signaling factors, was also significantly increased indicating a general enhancement of PI3K/Akt signaling pathway in InsR silenced cells (Figure 3B). These results were confirmed by measurement of Akt activity (Figure 3C). Cell lysates were also subject to Ras pull-down assay and Western blotting for Erk1/2. InsR silencing induced significant decreases in Ras activity and phosphorylation of Erk $1 / 2$, indicating a suppression of Ras/Erk1/2 (Figure 3D,E).

\section{Attenuation of FN accumulation depends on PI3K/Akt signaling in the InsR silenced cells}

In order to clarify how alteration in PI3K/Akt and Ras/ Erk1/2 signaling pathways contributed to attenuation of cellular FN accumulation, we co-transfected a dominant negative (DN)-Akt or a constitutively activated H-Ras cDNA to the InsR silenced cells. Lysates from these cells were subject to Western blotting with anti-FN antibody to determine the effects of suppression of PI3K/Akt or enhancement of Ras/Erk1/2 on FN accumulation. As expected, silencing of InsR resulted in a significant reduction in the cellular levels of FN. The reduction, however, were partially reversed by co-transfection of a DN-Akt cDNA. In contrast, co-transfection of a constitutively activated-H-Ras cDNA did not influence InsR silencing induced reduction in FN levels (Figure 4). These finding suggest InsR silencing induced attenuation in FN is partially dependent on PI3K/Akt but not on Ras/Erk1/2 pathway.

\section{PI3K/Akt activation depends on IGF-1R signaling in the InsR silenced cells}

As mentioned above, MCs express both InsR and IGF-1R. In order to investigate the involvement of IGF-1R in the augmented PI3K/Akt signaling pathway in the InsR silenced cells, we performed the following two experiments. First, the cells were incubated with vehicle (DMSO) or an IGF-1R specific antagonist, AG538 $(50 \mu \mathrm{M})$ for 12 hours, and the cell lysates were subject to in vitro immunoprecipitation lipid kinase assay to measure PI3K activity. Pharmacological blockade of IGF-1R effectively reversed the effect of InsR silencing on reducing PI3K activity (Figure 5A). The finding suggests that the elevated PI3K activity in InsR silenced cells was mediated by IGF-1R.

Next, we investigated sensitivity of the cells to exogenous IGF-1. The cells were stimulated with vehicle $\left(\mathrm{H}_{2} \mathrm{O}\right)$
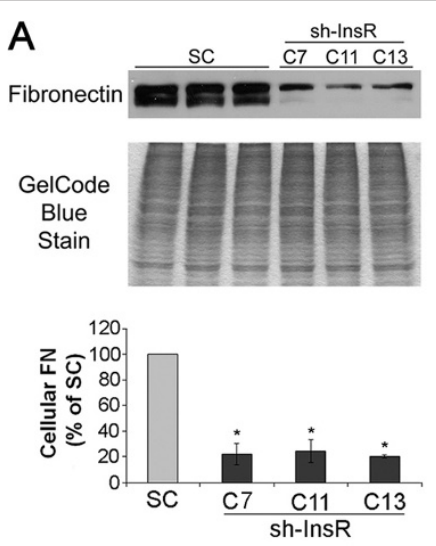
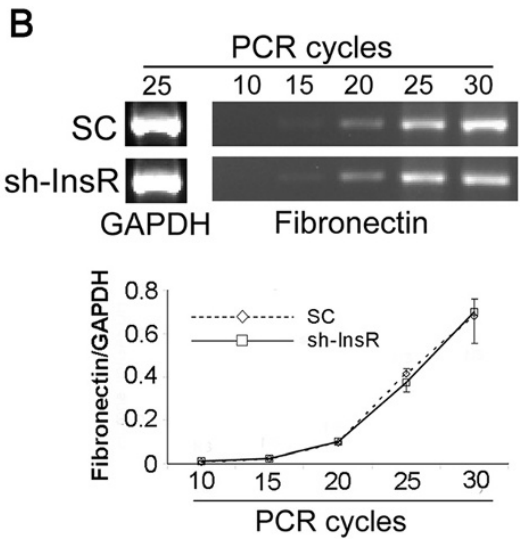

Figure 2 Silencing of InsR attenuated cellular accumulation of FN in MES-13 mesangial cells. (A) Immunoblotting with anti-FN antibody was performed on clones of InsR silenced cells and SC transfected cells. An image of gel stained after transfer was shown as a loading monitor (middle panel). Cellular FN levels were evaluated by densitometric analysis. Data are means \pm SEM from four independent experiments. ${ }^{*}, P<0.01$ versus SC transfected cells (lower panel). (B) Semi-quantitative analysis of FN mRNA levels in InsR silenced and SC transfected MES-13 cells. Total RNA isolated from quiescent cells was subject to RT-PCR using FN and GAPDH (internal control) specific primers with the indicated number of amplification cycles. One representative image from four independent experiments is shown (upper panel). FN transcription levels were evaluated by densitometric analysis. Data are means \pm SEM from four independent experiments. 


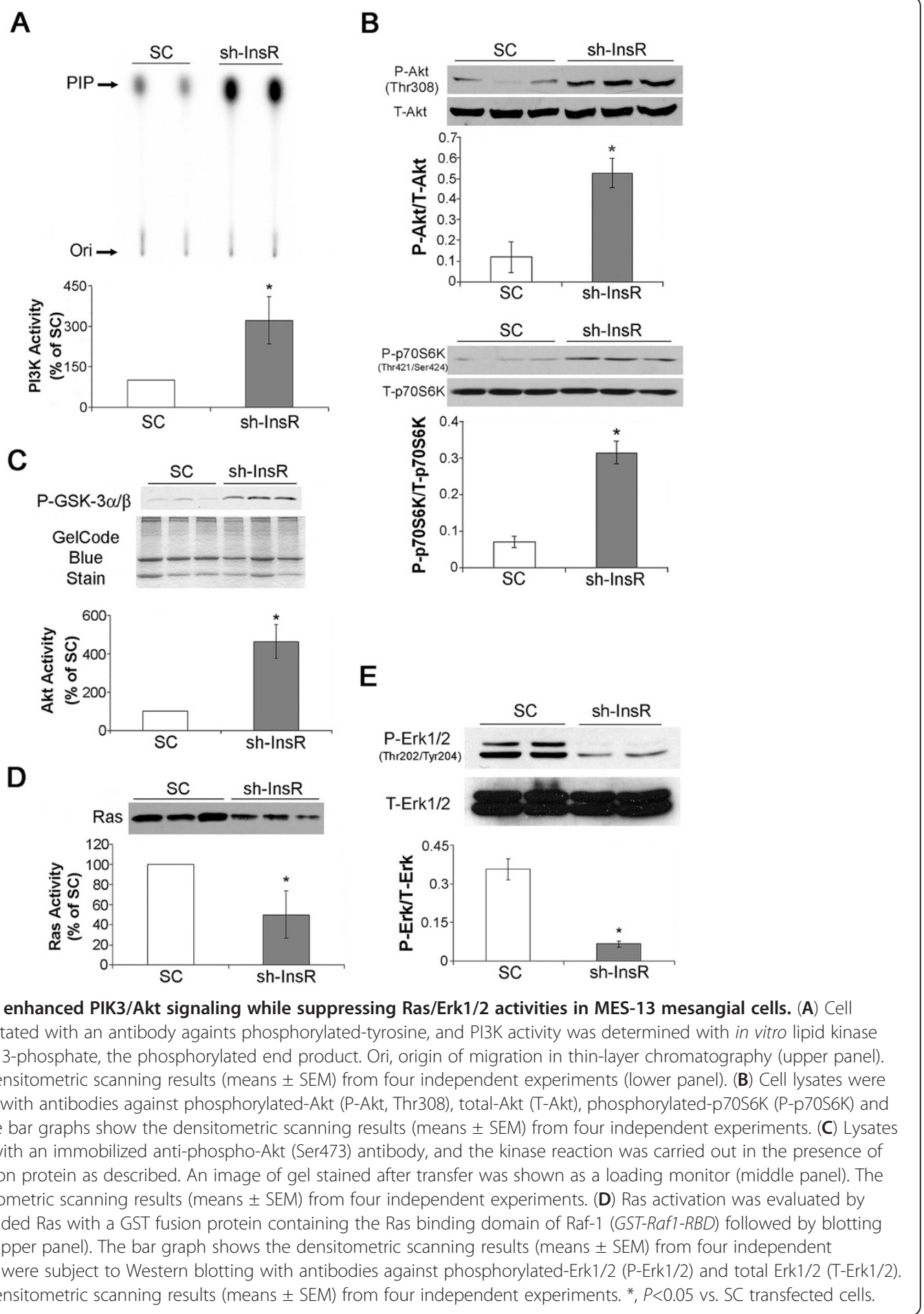

or a recombinant IGF-1 (rIGF-1, 10ng/mL) for 5 mintes, and the cell lysates were subject to in vitro immunoprecipitation lipid kinase assay to measure PI3K activity. The ratio of PI3K activity in rIGF-1 treated cells and vehicle treated cells were used as an indicator for cell sensitivity to IGF-1. In SC transfected cell, PI3K activity was significantly increased by rIGF-1 pretreatment (lanes 1, 3, Figure 5B). In InsR silenced cells, however, the increase in PI3K activity in response to rIGF-1 was even more significant (lanes 2, 4, Figure 5B). These results suggest an increase in sensitivity to IGF-1 in InsR silenced cells. 


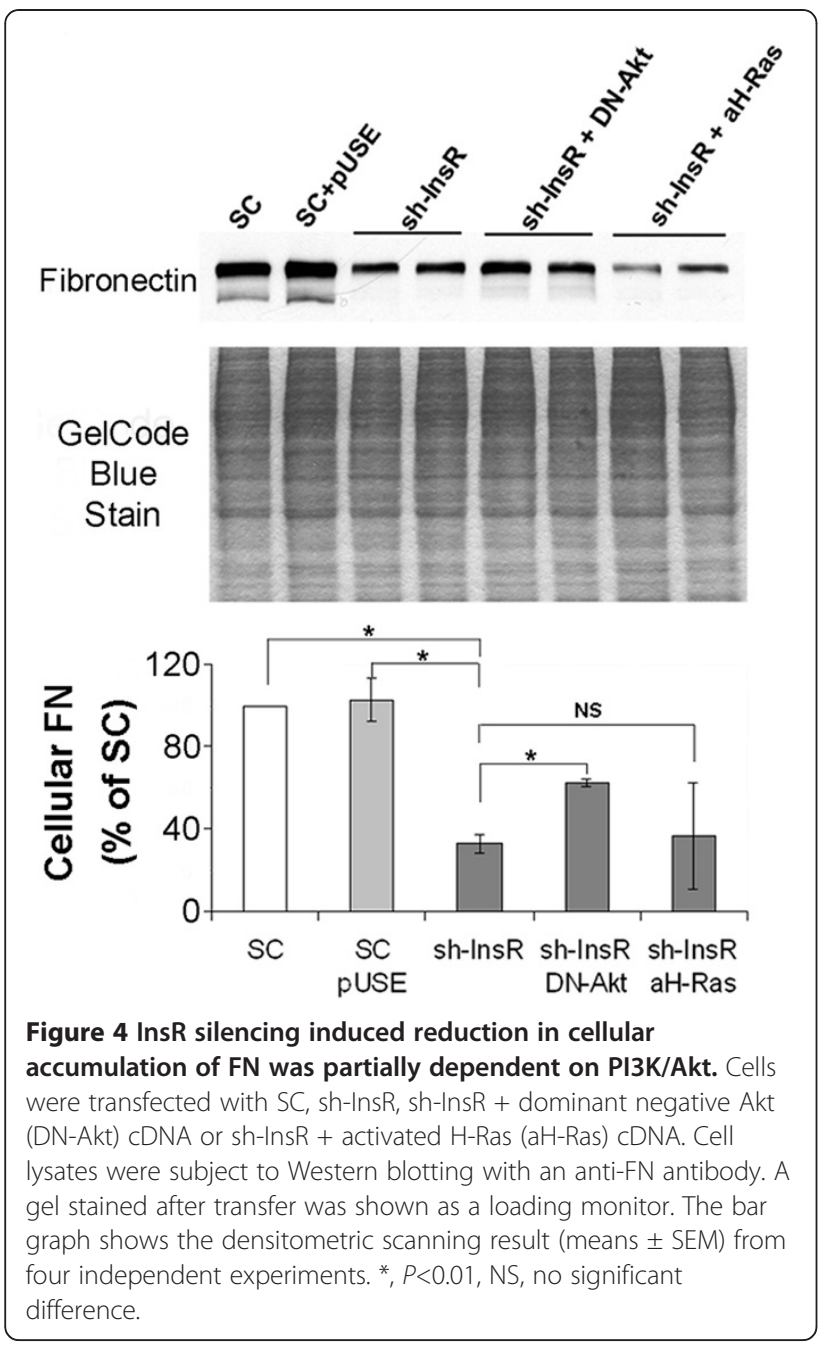

InsR silencing induces alteration in InsR/IGF-1R hybrid formation

InsR and IGF-1R are known to be originated from a common ancestral gene and sharing structures which are similar enough to form a hybrid receptor. To determine whether or not formation of hybrid receptors play a role in the observed activation of IGF-1R/PI3K/Akt signaling pathway in the InsR silenced cells, two set of experiments were performed. First, co-immunoprecipitation experiments were carried out in wild type (non-transfected) MES-13 cells. The results verified that IGF-1R and InsR can be reciprocally co-immunoprecipitated (Figure 6A). This confirmed specific detection of hybrid receptors, which form via random dimerization as a function of the molar fractions of the IGF-1R and InsR $[21,27,28]$. Suppressed expression of InsR would therefore be expected to affect the balance between formation of hybrid receptors and homodimers. Next, lysates from the SC transfected cells and InsR silenced cells were immunoprecipitated with anti-InsR $\alpha$ or anti-IGF-1R $\alpha$ antibody followed by immunoblotting with anti-IGF-1R $\beta$ for co-immunoprecipitation of hybrid receptors. Suppression of InsR resulted in 1) decreased IGF-1R coprecipitation, consistent with reduction in hybrid receptor formation (lanes 1-2, upper panel, Figure 6B); 2) increased formation of IGF-1R homodimers (lane 3-4, upper panel, Figure 6B). The latter was confirmed by immunoblotting the supernatants with anti-IGF-1R $\beta$. Detection of IGF-1R was significantly increased in the anti-InsR $\alpha$ immunoprecipitated supernatant from InsR silenced cells, indicating increased formation of IGF-1R homodimers (middle panel, Figure $6 \mathrm{~B}$ ). Taken together, InsR silencing resulted in reduced formation in IGF-1R/InsR hybrid receptor but increased formation of IGF-1R homodimer in MES-13 cells. These alterations in the balance of InsR and IGF-1R homodimer and hybrid receptor might contribute to the observed changes in signaling pathways in the InsR silenced cells.

\section{CREB-1-mediated MMP-9 expression leads to increased degradation of cellular FN in the InsR silenced cells} In the process for exploring the downstream factors which are involved in altered FN accumulation, a couple of unique phenotypes in InsR silenced cells were indentified. First, phosphorylation of CREB-1 is enhanced in the InsR silenced cells (Figure 7A). The elevated phosphorylation was effectively reversed by shutting down Akt activity by transfecting a dominant negative (DN)-Akt cDNA (Figure 7B). Second, expression of MMP-9 was increased in InsR silenced cells, and the increased expression was partially dependent on Akt or CREB-1 activity (Figure $7 \mathrm{C}$ ).

Next, we incubated cells with doxycycline $(10 \mu \mathrm{g} / \mathrm{mL})$, a broad-spectrum MMP inhibitor, for 72 hours, and then evaluated intracellular FN by Western blotting. As expected cellular accumulation of FN in InsR silenced cells was about $20 \%$ of that of SC transfected cells. Inhibition of MMP with doxycycline in InsR silenced cells effectively reversed the reduction in intracellular FN levels to about $70 \%$ of that of SC cells (Figure 6D). Taken together, these findings suggest that the attenuated cellular accumulation of FN in the InsR silenced cells was partially dependent on increased degradation by MMP which was induced by IGF-1R/PI3K/Akt/CREB-1 signaling pathways.

\section{Discussion}

In cells expressing both InsR and IGF-1R, InsR hemireceptors may heterodimerize with IGF-1R hemireceptors, leading to the formation of hybrid receptors (HRs). Heterodimerization of the two receptors is due to the high degree of homology between InsR and IGF-1R, which ranges from 27 to $84 \%$ depending on the region that is compared $[27,29]$. Heterodimerization is believed 

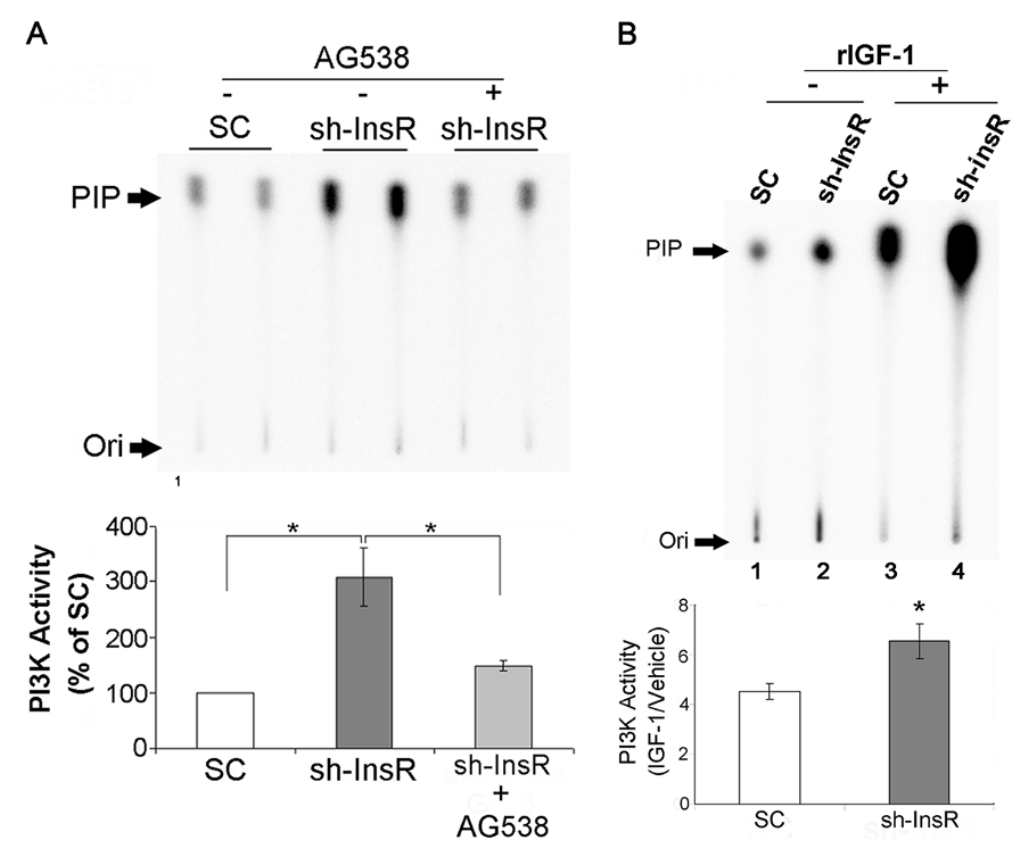

Figure 5 PI3K activation in InsR silenced cells was dependent on IGF-1R signaling. (A) Cells were incubated with AG538, an IGF-1R specific antagonist, or vehicle (DMSO) for 12 hours, and the cell lysates were subject to in vitro lipid kinase assay. PIP (phosphoinositide 3-phosphate), the phosphorylated end product. Ori, origin of migration in TLC. The bar graph shows the densitometric scanning results (means \pm SEM) from four independent experiments. ${ }^{*}, P<0.01$ vs. SC transfected cells. (B) Cells were treated with vehicle $\left(\mathrm{H}_{2} \mathrm{O}\right)$ or recombinant IGF-1 (rlGF-1, 10ng/mL) for 5 minutes, and the cell lysates were subject to in vitro lipid kinase assay (upper panel). Cell sensitivity to extrinsic IGF-1 is expressed as the ratio of PI3K activity in IGF-1 treated cells to that of vehicle treated cells. Data are means \pm SEM from four independent experiments. ${ }^{*}, P<0.05$ vs. SC transfected cells.

to occur with a similar efficiency as homodimerization. So the cellular proportions of homodimers and hybrids are supposed to be dependent on the expression ratios of each hemidimers [21-24,28,30]. Although, the physiological role of HRs is still unclear, early studies carried out with affinity chromatography-purified HRs indicated that these receptors mostly bind IGF-1 and that they bind insulin with much lower affinity $[24,31]$.

Findings in the present study suggested that silencing InsR caused increased formation of IGF-1R homodimers in MCs. It's possible that the change in the balance of the homodimers and hybrid receptors induced remarkable phenotypic changes of the attenuated cellular FN accumulation. Regardless of etiology, most end-stage glomerular diseases are characterized by accumulation of ECM proteins, including FN, in mesangium and other areas in glomeruli [1-3]. Over accumulation of the ECMs leads to sclerotic non-functional status of the kidney. So controlling the local ECM accumulation is believed to be one of the key therapeutic targets to prevent the development and progression of glomerular diseases. In spite of the extensive studies in the last decades, the mechanisms underlying this abnormal accumulation of ECM have not been fully elucidated. Our in vitro data suggested that alteration in the balance between InsR and IGF-1R and the resultant changes in PI3K/Akt signaling pathway contributed to the attenuation of cellular FN accumulation in MCs.

Expression of InsR is influenced by multiple factors. Estrogen showed inhibitory effect on Ir promoter activity [32]. In accordance with the negative effect of the estrogen, monocyte InsR content is higher during the luteal phases in adult females. This elevation is abolished by use of oral contraceptives or pregnancy [33]. Moreover, glucocorticoids and thyrotropin have been reported to enhance InsR expression while insulin down-regulates its cognate ligand [34-37]. Finally, nutrition and exercise have been reported to influence IR expression [38]. Various chronic glomerulopathy prone conditions such as poorly controlled diabetes, malignant tumors, systemic autoimmune diseases, pregnancy are inclinable to be accompanied endocrinological/metabolic disturbance which may affect expression of InsR or IGF-1R [39-42]. In these patients, appropriate control of the metabolic disturbance may potentially contribute to prevent the renal complications by correcting the InsR/IGF-1R balances.

IGF-1 has been shown to regulate protein synthesis in renal proximal tubular epithelial cells by activating both PI3K and Erk pathways [43]. Whereas, in the present study, InsR silencing caused increased PI3K activity and 


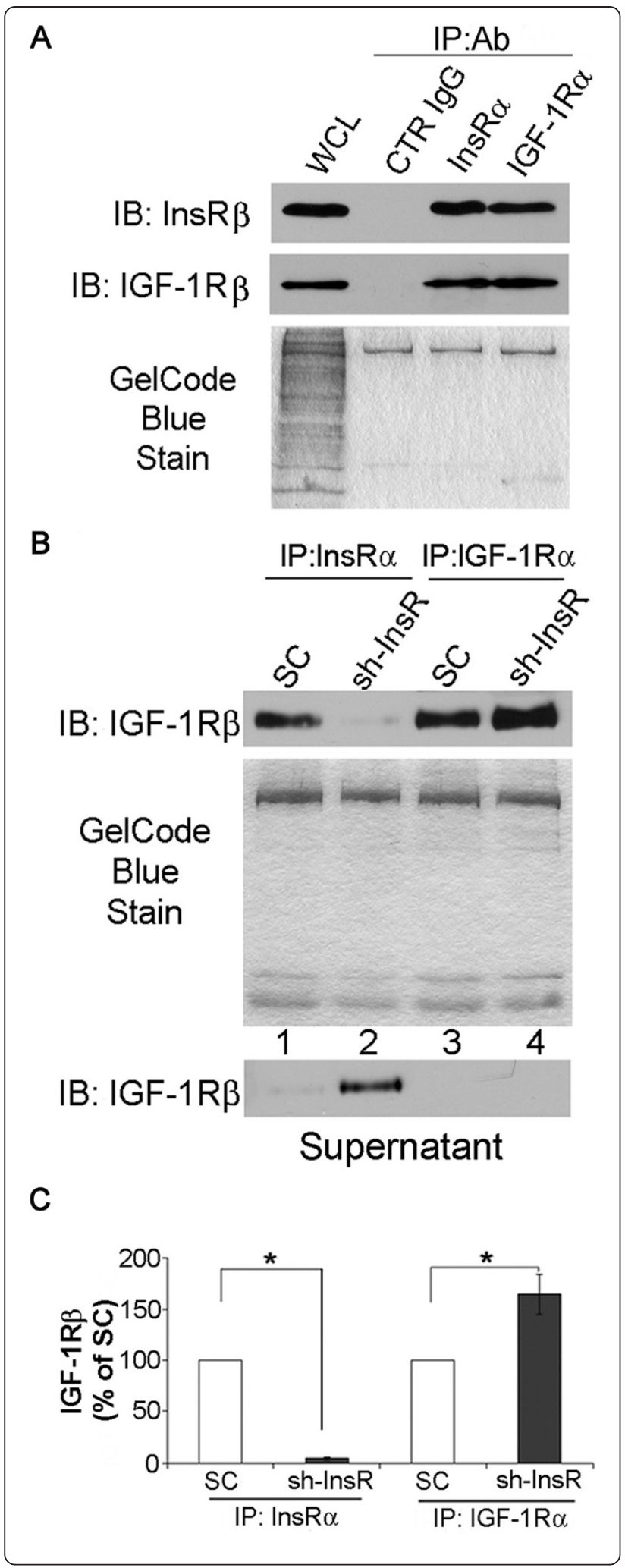

Figure 6 Silencing of InsR disrupted InsR/IGF-1R hybrid receptor formation and increased IGF-1R homodimer formation. (A) Lysates from non-transfected MES-13 mesangial cells were immunoprecipitaed (IP) using antibodies against IGF-1Ra, InsRa or control (CTR) IgG, an irrelevant control antibody.

Immunoprecipitates were immuneblotted (IB) for IGF-1Rß or InsR 3 . WCL, whole cell lysate. An image of gel stained after transfer was shown as a loading monitor (lower panel). (B) Hybrid receptors in SC or InsR shRNA (sh-InsR) transfected cells were detected by immunoprecipitation with antibodies directed against either the InsRa or IGF-1Ra. Immunoprecipitated receptors were detected by immunoblotting with an anti-IGF-1Rß antibody (upper panel). An image of gel stained after transfer was shown as a loading monitor. Immunodepletion was assessed by immunoblotting the supernatants from immunoprecipitate with an anti-IGF-1R $\beta$ antibody (middle panel). The bar graph shows the densitometric scanning results (upper panel, means \pm SEM) of four independents experiments *, $P<0.05$.

decreased Erk1/2 pathway activity. The reason for these discrepant findings has not been fully investigated but can be explained for the following: 1) we used renal glomerular MCs, which are specialized pericytes, whereas others used renal proximal tubular epithelial cells; 2) In our model, we showed silencing of InsR is associated with reduced Erk $1 / 2$ and increased PI3K activity. The latter can be blocked with IGF-1R inhibition. Hence, our experimental model is different from others that reported acute treatment with IGF-1 activates both PI3K and Erk1/2; 3) Altered InsR/IGF-1R balance may also be a factor for this characteristic phenotype of the InsR silenced MCs. Elucidating further details in the mechanisms will benefit understanding significance of InsR/ IGF-1R balance in the fibrotie phenotype switching in MCs.

The ECM accumulation can result from either increased synthesis or decreased degradation of ECM components or both. MMPs are one of the main contributors to degrade ECMs. Quite a few numbers of mechanisms for regulation of MMP activities and expressions in various tissues have been reported and our study is the first to describe the involvement of InsR/IGF-1R signaling in MMP expression. We also showed CREB-1 as a specific transcription factor to regulate MMP expression in our model. Based on these findings, we proposed a novel signaling model for regulation of cellular FN accumulation. In this model, silencing InsR promotes increased formation of IGF-1R homodimer which alters the activation status of downstream kinases. Enhanced activity of PI3K/Akt induces activation of CREB-1 and results in increased MMP expression to promote FN degradation. Since the MES-13 cells synthesize IGF-1 (Additional file 1) and since sensitivity to IGF-1 is increase in the InsR silenced MCs, in our in vitro model these endogenously produced IGF-1 possibly contributes 


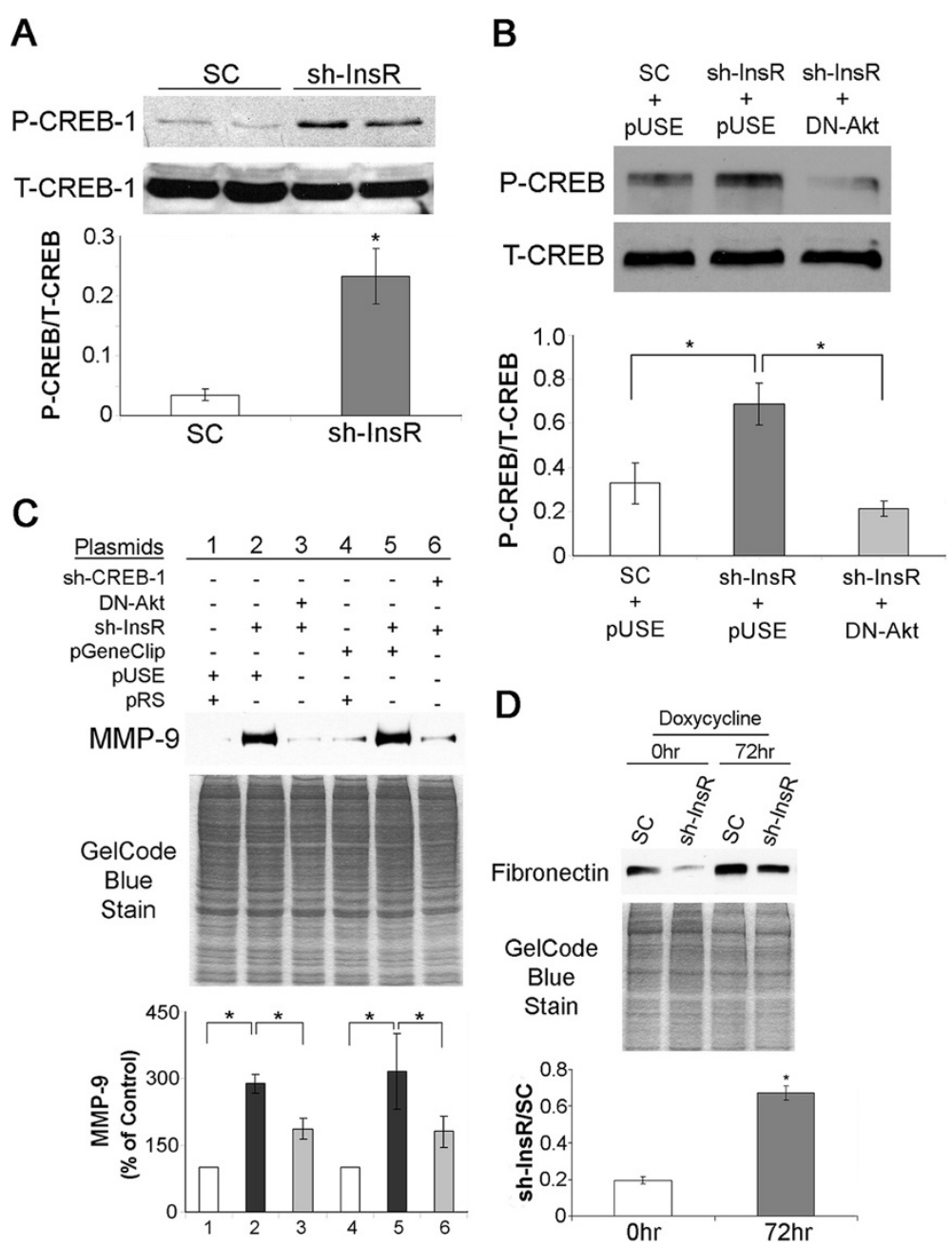

Figure 7 Increased MMP-9 expression and CREB-1 phosphorylation in InsR silenced cells. (A) Cell lysates from SC- and sh-InsR-transfected cells were subject to Western blotting using an antibody against phosphorylated (P-CREB-1) or total CREB-1 (T-CREB-1). The bar graph shows the densitometric scanning results (means \pm SEM) from four independent experiments. ${ }^{*}, P<0.01 \mathrm{vs}$. SC transfected cells. (B) Scrambled oligo (SC)- and sh-InsR-transfected cells were co-transfected with pUSEamp ${ }^{(+)}$empty vector or a dominant negative (DN)-Akt vector. Cell lysates were subject to Western blotting for CREB-1 as described in (A). The bar graph shows the densitometric scanning results (means \pm SEM) from four independent experiments. ${ }^{*}, P<0.01$ (lower panel). (C) Cells were stably co-transfected with plasmids as indicated and lysates were subject for Western blotting for MMP-9. pRS, a control plasmid for InsR shRNA; pUSE, pUSEamp ${ }^{(+)}$, a control plasmid for DN-Akt; pGeneClip, a control plasmid for CREB-1 shRNA (upper panel). An image of gel stained after transfer was shown as a loading monitor (middle panel). The bar graph shows the densitometric scanning results (means \pm SEM) from four independent experiments. ${ }^{*}, P<0.01$. (D) Scrambled oligo (SC)- and sh-InsR-transfected cells were incubated with doxycycline $(10 \mu \mathrm{g} / \mathrm{mL}, 72$ hours) and cell lysates were subject to Western blotting for FN. An image of gel stained after transfer was shown as a loading monitor (middle panel). The bar graph shows the densitometric scanning results (sh-InsR/SC, means \pm SEM) from four independents experiments. ${ }^{*}, P<0.01$.

to the observed changes in signaling pathways in an autocrine manner.

\section{Conclusions}

In summary, we have identified the phenotype of reduced cellular accumulation of FN in InsR silenced MCs. We explored the mechanisms underlying this unique phenotype. Our data suggest that the altered balance in the formation of InsR/IGF-1R homodimer and hybrid receptor is a crucial factor in the phenotype switching in MCs. We also demonstrated that resultant change in PI3K/Akt signaling pathway was involved in the induction of this phenotype. We further established that PI3K/Akt induced CREB-1 activation lead to enhanced MMP-9 expression which was likely involved in reduced $\mathrm{FN}$ accumulation by enhancing degradation of FN. These findings provide important information for largely unknown mechanisms in InsR/IGF-1R mediated myofibroblast transdifferentiation (MFT) of MCs in glomerulopathies. Elucidating further details in this signaling 
pathway will benefit future choices of treatment for glomerulosclerosis.

\section{Materials and methods \\ Cell culture}

MES-13 mouse mesangial cells (ATCC \#CRL-1927) were grown in a 3:1 mixture of Dulbecco's modified Eagle's and Ham's F-12 media (Invitrogen) supplemented with $5 \%(\mathrm{v} / \mathrm{v})$ fetal bovine serum containing 50 units $/ \mathrm{ml}$ penicillin $\mathrm{G}$ and $50 \mu \mathrm{g} / \mathrm{ml}$ streptomycin in a humidified atmosphere containing $5 \% \mathrm{CO}_{2}$ at $37^{\circ} \mathrm{C}$. Cells were first grown up to $90 \%$ confluence and synchronized overnight in serum-free medium prior to treatment. In some experiments cells were treated with recombinant IGF-1 (Invitrogen) or AG538 (EMD Chemical), an IGF-1R selective inhibitor, for the indicated durations.

\section{PI3K Assays}

PI3K activity in cell lysate was determined with in vitro mmunoprecipitation lipid kinase assay as described previously [44]. Briefly, cell lysates $(0.5 \mathrm{mg})$ were immunoprecipitated with anti-phosphotyrosine (anti-pY) antibody (Millipore), and L- $\alpha$-phosphoinositide (Avanti Polar Lipids) was used as the lipid substrate ( $2 \mu \mathrm{g} /$ reaction). After incubation, the final extracted reaction mixtures were spotted onto silica gel-coated TLC plates (Whatman) and run in TLC buffer (65\% $n$-propanol, $0.54 \mathrm{M}$ acetic acid).

\section{Antibodies}

Antibody against fibronectin was purchased from Millipore. Antibodies against InsR $\alpha$, InsR $\beta, I G F-1 R \alpha$ and phospholylated or total CREB-1 were purchased from Santa Cruz Biotechnology. Antibodies against phosphorylated or total Akt, phosphorylated or total Erk1/2 and phosphorylated or total p70S6, IGF-1R $\beta$ and MMP-9 were purchased from Cell Signaling Technology.

\section{Immunoprecipitation}

For immunoprecipitation, protein lysates $(0.5 \mathrm{mg})$ were incubated with an antibody specific for InsR $\alpha$ or IGF$1 \mathrm{R} \alpha$ at $4^{\circ} \mathrm{C}$ for 4 hours with continuous rotation. After the incubation, a 20- $\mu$ l packed volume of protein GSepharose (GE-Health Care) was added to the lysates and incubated for another 4 hours at $4^{\circ} \mathrm{C}$. After washing, $45 \mu$ of $1 \times$ Laemmli sample buffer was added to the beads. The sample was heated in boiling water for 5 minutes and quenched on ice for 2 minutes. After vortex and centrifuge, $20 \mu \mathrm{l}$ of the supernatant was resolved on a $7.5 \%$ SDS-PAGE gel and immunoblotted with appropriate antibody.

\section{Pull down assay for Ras activity}

Cells were lysed in $\mathrm{Mg}^{2+}$ IP buffer (25mM HEPES, $\mathrm{pH} 7.7,150 \mathrm{mM} \mathrm{NaCl}, 1 \%$ Igepal CA-630, 10mM $\mathrm{MgCl}_{2}$, $1 \mathrm{mM}$ EDTA and $2 \%$ glycerol). Cleared cell lysates were normalized with the BCA assay (Santa Cruz Biotechnology). Normalized cell lysates were incubated with Raf-1 RBD preconjugated agarose (Millipore) for 2 hours at $4^{\circ} \mathrm{C}$. Pelleted agarose were washed three times with IP buffer. Protein bound to the beads was eluted with 1xLaemmli's buffer and subject to $12 \%$ SDSpolyacrylamide gel electrophoresis (SDS-PAGE). Ras was detected with a specific monoclonal antibody (clone Ras10, Millipore).

\section{In vitro IP Akt activity assay}

Cells were serum-starved for 16 hours, and then washed twice with phosphate-buffered saline and lysed in icecold lysis buffer (20mM Tris, $\mathrm{pH} 7.4,150 \mathrm{mM} \mathrm{NaCl}$, 1\% Triton X-100, 1mM EDTA, 1mM EGTA, 2.5mM sodium pyrophosphate, $1 \mathrm{mM} \beta$-glycerolphosphate, $1 \mathrm{mM}$ sodium orthovanadate, $1 \mu \mathrm{g} / \mathrm{ml}$ leupeptin, and $1 \mathrm{mM}$ phenylmethylsulfonyl fluoride). The extracts were centrifuged to remove cellular debris, and normalized by BCA assay (Santa Cruz). $250 \mu \mathrm{g}$ of protein from the lysate samples was incubated with gentle rocking at $4^{\circ} \mathrm{C}$ overnight with immobilized anti-phospho-Akt (Ser473) antibody crosslinked to sepharose beads (Cell Signaling Technology). After phosphorylated Akt was selectively immunoprecipitated from the cell lysates, the immunoprecipitated products were washed twice in lysis buffer and twice in kinase assay buffer $(25 \mathrm{mM}$ Tris, $\mathrm{pH} 7.5,10 \mathrm{mM}$ $\mathrm{MgCl}_{2}, \quad 50 \mathrm{mM} \quad \beta$-glycerolphosphate, $0.1 \mathrm{mM}$ sodium orthovanadate, and $2 \mathrm{mM}$ dithiothreitol), and the samples were resuspended in $40 \mu \mathrm{l}$ of kinase assay buffer containing $200 \mu \mathrm{M}$ ATP and $1 \mu \mathrm{g}$ of GSK-3 $\alpha$ fusion protein. The kinase reaction was allowed to proceed at $30^{\circ} \mathrm{C}$ for 30 minutes and stopped by the addition of Laemmli SDS sample buffer. Reaction products were resolved by $15 \%$ SDS-PAGE followed by Western blotting with an antiphospho-GSK-3 $\alpha / \beta$ antibody (Cell Signaling Technology).

\section{Stable transfection}

A vector expressing shRNA against InsR was purchased from Santa Cruz Biotechnology. A vector expressing shRNA against CREB1 was purchased from SABioscience. A vector expressing dominant negative Akt1 was engineered by inserting a K179M mutant dominant negative Akt1 cDNA (Millipore) into a multiple cloning site of a eukaryotic expression vector, pUSEamp(+) (Millipore). A 529F mutant constitutively activated H-Ras cDNA (Millipore) was processed similarly to engineer a vector expressing constitutively activated H-Ras. Stable transfection of the constructs in MES-13 cells was performed using Lipofectamine 2000 (Invitrogen) according to the 
manufacturer's instructions. Individual single cells were isolated and screened for neomycin or puromycin resistance. Phenotypes of the transfected cells were examined by Western blotting, IP Akt assay or Ras pull-down assay (Figure 1, Additional files 2, 3, 4).

\section{RT-PCR}

Total RNA was isolated from cells using TRIzol reagent (Invitrogen). Reverse transcription was carried out on total RNA using SuperScript III (Invitrogen) followed by PCR using gene specific primers (Additional file 5).

\section{Statistical analysis}

Statistical significance of the difference among groups was analyzed by the paired Student's t test or parametric ANOVA and Ryan's multiple comparison test using Microsoft Exel (Microsoft) and ANOVA4 on the Web (http://www.hju.ac.jp/ kiriki/anova4/). All data were represented as the mean \pm SEM of four different experiments unless otherwise noted in the figure legends. A probability of $p<0.05$ was considered to represent a significant difference.

\section{Additional files}

Additional file 1: MES-13 mesangial cells produce intrinsic IGF-1. (A) Lysates from quiescent control (SC) and InsR silenced (sh-InsR) cells were subject to immunoblotting with antibody against IGF-1. An image of gel stained after transfer was shown as a loading monitor. (B) Total RNA isolated from quiescent cells was subject to RT-PCR using IGF-1 and GAPDH (internal control) specific primers.

Additional file 2: Phenotyping of activated H-Ras transfected cells. (A) Ras activities of the InsR shRNA and activated H-Ras double transfected cells were evaluated by Ras pull-down assay as described under "Materials and methods". Clones, \#2, 4 and 8 were used for the experiments. (B) Phosphorylation of Erk1/2 of the selected clones were evaluated by Western blotting. P-Erk1/2, phosphorylated Erk1/2; T-Erk1/2, total Erk1/2.

Additional file 3: Phenotyping of DN-Akt transfected cells. Akt activities of InsR sh-RNA and DN-Akt double transfected cells were evaluated by IP Akt activity assay as described under "Materials and methods". Clones \#3 and 7 were used for the experiments.

Additional file 4: Phenotyping of CREB-1 shRNA transfected cells. CREB-1 levels in InsR and CREB-1 shRNA double transfected cells were evaluated by Western blotting. An image of gel stained after transfer was shown as a loading monitor. Clones \#1, 4 and 5 were used for the experiments.

\section{Additional file 5: PCR primer sequences for fibronectin, IGF-1 and} GAPDH.

\section{Competing interests}

The authors declare that they have no competing interests.

\section{Authors' contributions}

NY designed and performed the experiments, analyzed the data, and wrote the paper. DS, ME, WZ, YCX, JFP and Y-TT critically revised the manuscript prior to the initial submission. All authors read and approved the final manuscript.

\section{Acknowledgements}

Funding: (1) National Center for Research Resources (5P20RR018728-10) and the National Institute of General Medical Sciences (8 P20 GM103537-10) from the National Institutes of Health (Y-TT and JFP). (2) Natural Science

Foundation of China (81200087 to WZ)

\section{Author details}

'Department of Pediatrics, Women \& Infants Hospital, The Warren Alpert Medical School of Brown University, Providence, Rl 02905, USA. ${ }^{2}$ Division of Nephrology and Metabolism, Tokai University School of Medicine, Isehara, Kanagawa 259-1193, Japan. ${ }^{3}$ Department of Cardiothoracic Surgery, The Second Xiangya Hospital, Central South University, Changsha, China

Received: 16 July 2012 Accepted: 5 October 2012

Published: 12 October 2012

\section{References}

1. Tomino Y, Nomoto Y, Sakai H: Immunofluorescent studies on IgA nephropathy: type IV collagen and glomerular basement membrane component detected by Goodpasture's syndrome serum and laminin. Tokai J Exp Clin Med 1988, 13:137-143.

2. Razzaque MS, Kumatori A, Harada T, Taguchi T: Coexpression of collagens and collagen-binding heat shock protein 47 in human diabetic nephropathy and IgA nephropathy. Nephron 1998, 80:434-443.

3. Gooch JL, Barnes JL, Garcia S, Abboud HE: Calcineurin is activated in diabetes and is required for glomerular hypertrophy and ECM accumulation. Am J Physiol Renal Physiol 2003, 284:F144-F154.

4. Santiago A, Satriano J, Decandido S, Holthofer H, Schreiber R, Unkeless J, Schlondorff D: A specific Fcy receptor on cultured rat mesangial cells. J Immunol 1989, 143:2575-2582.

5. Lenz O, Elliot SJ, Stetler-Stevenson WG: Matrix metalloproteinases in renal development and disease. J Am Soc Nephrol 2000, 11:574-581.

6. Schnaper HW, Kopp JB, Poncelet AC, Hubchak SC, Stetler-Stevenson WG, Klotman PE, Kleinman HK: Increased expression of extracellular matrix proteins and decreased expression of matrix proteases after serial passage of glomerular mesangial cells. J Cell Sci 1996, 109:2521-2528.

7. Huang S, Schaefer RM, Reisch S, Paczek L, Schaefer L, Teschner M, Sebekova K, Heidland A: Suppressed activities of cathepsins and metalloproteinases in the chronic model of puromycin aminonucleoside nephrosis. Kidney Blood Press Res 1999, 22:121-127.

8. Ebihara I, Nakamura T, Tomino Y, Koide H: Effect of a specific endothelin receptor $\mathrm{A}$ antagonist and an angiotensin converting enzyme inhibitor on glomerular mRNA levels for extracellular matrix components, metalloproteinases (MMP) and a tissue inhibitor of MMP in aminonucleoside nephrosis. Nephrol Dial Transplant 1997, 12:1001-1006.

9. Davies M, Martin J, Thomas GJ, Lovett DH: Proteinases and glomerular matrix turnover. Kidney Int 1992, 41:671-678.

10. Norman JT, Lewis MP: Matrix metalloproteinases (MMPs) in renal fibrosis. Kidney Int 1996, 49:S61-S63.

11. Fornoni A, Rosenzweig SA, Lenz O, Rivera A, Striker GE, Elliot SJ: Low insulin-like growth factor binding protein-2 expression is responsible for increased insulin receptor substrate-1 phosphorylation in mesangial cells from mice susceptible to glomerulosclerosis. Endocrinology 2006, 147:3547-3554

12. Lupiáñez JA, Dileepan KN, Wagle SR: Interrelationship of somatostatin, insulin, and calcium in the control of gluconeogenesis in kidney cortex slices. Biochem Biophys Res Commun 1979, 90:1153-1158.

13. Mima A, Ohshiro Y, Kitada M, Matsumoto M, Geraldes P, Li C, Li Q, White GS, Cahill C, Rask-Madsen C, King GL: Glomerular-specific protein kinase C-induced insulin receptor substrate-1 dysfunction and insulin resistance in rat models of diabetes and obesity. Kidney Int 2011, 79:883-896.

14. Baum M: Insulin stimulates volume absorption in the rabbit proximal convoluted tubule. J Clin Invest 1987, 79:1104-1109.

15. Mandon B, Siga E, Chabardes D, Firsov D, Roinel N, De Rouffignac C: Insulin stimulates $\mathrm{Na}^{+}, \mathrm{Cl}, \mathrm{Ca}^{2+}$, and $\mathrm{Mg}^{2+}$ transports in TAL of mouse nephron: cross-potentiation with AVP. Am J Physiol Renal Physiol 1993, 265:F361-F369.

16. Ito O, Kondo Y, Takahashi N, Kudo K, Igarashi Y, Omata K, Imai Y, Abe K: Insulin stimulates $\mathrm{NaCl}$ transport in isolated perfused MTAL of Henle's loop of rabbit kidney. Am J Physiol 1994, 267:F265-F270 
17. Takahashi N, Ito O, Abe K: Tubular effects of insulin. Hypertens Res 1996, 19:\$41-S45.

18. Ullrich A, Bell JR, Chen EY, Herrera R, Petruzzelli LM, Dull TJ, Gray A, Coussens L, Liao Y-C, Tsubokawa M, Mason A, Seeburg PH, Grunfeld C, Rosen OM, Ramachandran J: Human insulin receptor and its relationship to the tyrosine kinase family of oncogenes. Nature (London) 1985, 313:756-761.

19. Olson TS, Bamberger MJ, Lane MD: Post-translational changes in tertiary and quaternary structure of the insulin proreceptor. Correlation with acquisition of function. J Biol Chem 1988, 263:7342-7351.

20. Seino $S$, Seino $M$, Nishi $S$, Bell Gl: Structure of the human insulin receptor gene and characterization of its promoter. Proc Natl Acad Sci USA 1989, 86:114-118.

21. Bailyes EM, Navé BT, Soos MA, Orr SR, Hayward AC, Siddle K: Insulin receptor/IGF-1 receptor hybrids are widely distributed in mammalian tissues: quantification of individual receptor species by selective immunoprecipitation and immunoblotting. Biochem J 1997, 327:209-215.

22. Belfiore A, Frasca F, Pandini G, Sciacca L, Vigneri R: Insulin receptor isoform and insulin receptor/insulin-like growth factor receptor hybrids in physiology and disease. Endocr Rev 2009, 30:586-623.

23. Soos MA, Field CE, Siddle K: Purified hybrid insulin/insulin-like growth factor-I receptors bind insulin-like growth factor-I, but not insulin, with high affinity. Biochem J 1993, 290:419-426.

24. Kasuya J, Benjamin Paz I, Maddux BA, Goldfine ID, Hefta SA, FujitaYamaguchi Y: Characterization of human placental insulin-like growth factor-l/insulin hybrid receptors by protein microsequencing and purification. Biochemistry 1993, 32:13531-13536.

25. Moxham CP, Duronio V, Jacobs S: Insulin-like growth factor I receptor $\beta$-subunit heterogeneity. Evidence for hybrid tetramers composed of insulin-like growth factor I and insulin receptor heterodimers. J Biol Chem 1989, 264:13238-13244.

26. Yano N, Endoh M, Fadden KJ, Yamashita H, Sakai H, Kurokawa K, Abboud $H E$, Rifai A: Genomic repertoire of human mesangial cells: comprehensive analysis of gene expression by cDNA array hybridization. Nephrology 2000, 5:215-223.

27. Denly A, Cosgrove LJ, Booker GW, Wallace JC, Forbes BE: Molecular interactions of the IGF system. Cytokine Growth Factor Rev 2005, 16:421-439.

28. Federici M, Porzio O, Zucaro L, Fusco A, Borboni P, Lauro D, Sesti G: Distribution of insulin/insulin-like growth factor-I hybrid receptors in human tissues. Mol Cell Endocrinol 1997, 129:121-126.

29. De Meyts P: Insulin and its receptor: structure, function and evolution. Bioessays 2004, 26:1351-1362.

30. Treadway Jl, Morrison BD, Goldfine ID, Pessin JE: Assembly of insulin/ insulin-like growth factor-1 hybrid receptors in vitro. J Biol Chem 1989, 264:21450-21453.

31. Langlois WJ, Sasaoka T, Yip CC, Olefsky JM: Functional characterization of hybrid receptors composed of a truncated insulin receptor and wild type insulin-like growth factor 1 or IRs. Endocrinology 1995, 136:1978-1986.

32. García-Arencibia M, Dávila N, Campión J, Carmen Carranza M, Calle C: Identification of two functional estrogen response elements complexed with AP-1-like sites in the human insulin receptor gene promoter. J Steroid Biochem Mol Biol 2005, 94:1-14.

33. Tsibris JC, Raynor LO, Buhi WC, Buggie J, Spellacy WN: Insulin receptors in circulating erythrocytes and monocytes from women on oral contraceptives or pregnant women near term. J Clin Endocrinol Metab 1980, 51:711-717.

34. Shibasaki $Y$, Sakura H, Odawara M, Shibuya M, Kanazawa $Y$, Akanuma $Y$, Takaku F, Kasuga M: Glucocorticoids increase insulin binding and the amount of insulin-receptor mRNA in human cultured lymphocytes. Biochem J 1988, 249:715-719.

35. Burikhanov R, Coulonval K, Pirson I, Lamy F, Dumont JE, Roger PP: Thyrotropin via cyclic AMP induces insulin receptor expression and insulin Co-stimulation of growth and amplifies insulin and insulin-like growth factor signaling pathways in dog thyroid epithelial cells. J Bioll Chem 1996, 271:29400-29406.

36. Mamula PW, McDonald AR, Brunetti A, Okabayashi Y, Wong KY, Maddux BA, Logsdon C, Goldfine ID: Regulating insulin-receptor-gene expression by differentiation and hormones. Diabetes Care 1990, 13:288-301.

37. Kaplan SA: The insulin receptor. J Pediatric 1984, 104:327-336.
38. Pedersen $\mathrm{O}$, Beck-Nielsen $\mathrm{H}$, Heding L: Increased IRs after exercise in patients with insulin-dependent diabetes mellitus. N Engl J Med 1980, 302:886-892.

39. Stern MP, Haffner SM: Body fat distribution and hyperinsulinemia as risk factors for diabetes and cardiovascular disease. Arteriosclerosis 1986, 6:123-130.

40. Ghalaut VS, Yadav S, Ghalaut PS, Yadav A, Sachdeva A, Yadav R, Sharma TK Shankar V: Association of insulin like growth factor-1 (IGF-1) and thyroid hormones in patients of acute leukemia. Clin Lab 2012, 58:227-231.

41. Mader R, Mishail S, Adawi M, Lavi I, Luboshitzky R: Thyroid dysfunction in patients with systemic lupus erythematosus (SLE): relation to disease activity. Clin Rheumatol 2007, 26:1891-1894.

42. Beck-Nielsen H, Kühl C, Pederson O, Bjerre-Christensen C, Nielsen TT, Klebe JG: Decreased insulin binding to monocytes from normal pregnant women. J Clin Endocrinol Metab 1979, 49:810-814.

43. Senthil D, Choudhury GG, Abboud HE, Sonenberg N, Kasinath BS: Regulation of proteinsynthesis by IGF-1 in proximal tubular epithelial cells. Am J Physiol Renal Phsyol 2002, 283:F1226-F1236.

44. Tseng Y-T, Yano N, Rojan A, Stabila JP, McGonnigal BG, lanus V, Wadhawan R, Padbury JF: Ontogeny of phosphoinositide 3-kinase signaling indeveloping heart: effect of acute $\beta$-adrenergic stimulation. Am J Physiol Heart Circ Physiol 2005, 289:H1834-H1842.

doi:10.1186/1478-811X-10-29

Cite this article as: Yano et al:: In vitro silencing of the insulin receptor attenuates cellular accumulation of fibronectin in renal mesangial cells. Cell Communication and Signaling 2012 10:29.

\section{Submit your next manuscript to BioMed Central and take full advantage of:}

- Convenient online submission

- Thorough peer review

- No space constraints or color figure charges

- Immediate publication on acceptance

- Inclusion in PubMed, CAS, Scopus and Google Scholar

- Research which is freely available for redistribution 